\title{
Explaining the longevity characteristics in China from a geographical perspective: A multi-scale geographically weighted regression analysis
}

\author{
Renfei Yang, ${ }^{1}$ Fu Ren, ${ }^{1,2}$ Xiangyuan Ma, ${ }^{1}$ Hongwei Zhang, ${ }^{3}$ Wenxuan Xu, ${ }^{4}$ Peng Jia ${ }^{1,5}$ \\ ${ }^{1}$ School of Resource and Environmental Science, Wuhan University, Wuhan; ${ }^{2}$ Key Laboratory of GIS, \\ Ministry of Education, Wuhan University, Wuhan; ${ }^{3}$ Electronic Information School, Wuhan University, \\ Wuhan; ${ }^{4}$ School of Geographic and Oceanographic Sciences, Nanjing University, Nanjing; ${ }^{5}$ International \\ Institute of Spatial Lifecourse Epidemiology (ISLE), Wuhan University, Wuhan, China
}

\begin{abstract}
Longevity is a near-universal human aspiration that can affect moral progress and economic development at the social level. In rapidly developing China, questions about the geographical distribution and environmental factors of longevity phenomenon need to be answered more clearly. This study calculated the longevity index (LI), longevity index for females (LIF) and longevity index for males (LIM) based on the percentage of the long-lived population among the total number of elderly people to investigate regional and gender characteristics at the county level in China. A new multi-scale geographically weighted regression (MGWR) model and four possible geographical environmental factors were applied to explore environmental effects. The results indicate that the LIs of 2838 counties ranged from $1.3 \%$ to $16.3 \%$, and the distribution showed obvious regional and gender differences. In gen-
\end{abstract}

Correspondence: Fu Ren, School of Resource and Environmental Science, Wuhan University, 129 Luoyu Road, Wuhan 430079, China. Tel.: +86.27.68778675 - Fax: +86.27 .68778893 .

E-mail: renfu@whu.edu.cn

Key words: Longevity; geographical environmental factors; county level; multi-scale geographically weighted regression; influence scale; China.

Acknowledgements: this study was supported by the National Natural Science Foundation of China (42071448) and the International Institute of Spatial Lifecourse Epidemiology (ISLE).

Contributions: the authors contributed equally.

Conflict of interest: the authors declare no potential conflict of interest.

Received for publication: 9 June 2021.

Revision received: 24 October 2021.

Accepted for publication: 5 November 2021.

CCopyright: the Author(s), 2021

Licensee PAGEPress, Italy

Geospatial Health 2021; 16:1024

doi:10.4081/gh.2021.1024

This article is distributed under the terms of the Creative Commons Attribution Noncommercial License (CC BY-NC 4.0) which permits any noncommercial use, distribution, and reproduction in any medium, provided the original author(s) and source are credited. eral, the LI was high in the East and low in the West, and the LIF was higher than the LIM in 2614 counties (92.1\%). The MGWR model performed well explaining that geographical environmental factors, including topographic features, vegetation conditions, human social activity and air pollution factors have a variable influence on longevity at different spatial scales and in different regions. These findings enrich our understanding of the spatial distribution, gender differences and geographical environmental effects on longevity in China, which provides an important reference for people interested in the variations in the associations between different geographical factors.

\section{Introduction}

Although longevity occurs in individuals, some geographic patterns have been observed in the distribution of long-lived individuals (Romanski et al., 2015; Montesanto et al., 2017). Investigating modifiable factors underlying those patterns has drawn much attention from a broad array of research areas (Wang et al., 2016; Jia et al., 2019; Jia et al., 2020; Vierboom and Preston, 2020). Approximately two decades ago, a geographic area with high longevity rates was defined for the first time as a Blue Zone in a study conducted in Sardinia, Italy (Poulain et al., 2004). Since then, this concept has been applied by scholars across the world and Okinawa in Japan, Loma Linda in California, USA, and Nicoya in Costa Rica have also participated in the Blue Zones Project (Chrysohoou et al., 2011; Poulain et al., 2013). In the $21^{\text {st }}$ century, when the number of people living longer was expected to increase greatly (Robine and Cubaynes, 2017), Blue Zones have become an important indicator of geographical environmental characteristics that may contribute to longevity. This could provide evidence also for other regions to optimize their environmental conditions for improving the overall health and well-being of their residents.

In China, the ageing problem has become increasingly serious (Wang et al., 2016). Similar to the Blue Zone, the concept of longevity area was proposed by the China Association of Gerontology and Geriatrics (CAGG), which established a set of evaluation indicators and measured the counties applying for recognition through expert scores (CAGG, 2019). As of January 2021,87 counties have been recognized as longevity areas in China, and industries related to longevity, such as tourism, health care, recuperation and finance are expected to develop in these counties (CAGG, 2021). The accreditation process combines quantitative evaluation indicators with expert experience to answer the question of where to live longer, but it still fails to identify longevity areas that have not applied for recognition. In a 
study evaluating the ageing process of the Italian population, a longevity index (LI) was defined as the proportion of the longlived population to the elderly population (Magnolfi et al., 2007). With its simplicity and effectiveness, this index has been used to analyse the patterns and influential factors of the longevity phenomenon in China (Lv et al., 2011; Liu et al., 2014; Song et al., 2016). Unfortunately, limited by the complexity of census data processing, these studies used provinces or other typical regions as basis. Because China's provincial regions are so large, the answer to where to live longer is too vague in studies based on them. In contrast, resources and environmental conditions are more homogeneous at the county level, which is the basic administrative division in China and more suitable to identify longevity areas at the national scale. In addition, there has been a lack of research on gender differences and potential geographical environmental influences of the Chinese longevity areas. In terms of the demographic characteristics of longevity, females generally tend to live longer than males, even if they live in the same geographical environment. This is seen in many places, e.g., Greece and England (Johnson et al., 2020; Zafeiris, 2020) and may also be true for China. Previous studies have shown that the life expectancy of Chinese men in 2010 was 73 years, while that of women was 78 years (Zhang and Wei, 2016). However, until now, there have been few discussions of the spatial distribution of longevity from the perspective of gender.

The longevity phenomenon has been generally influenced by geographical environmental factors, but these factors are complex and varied. Taking topography as an example, Lv et al. (2011) found that elevation is positively correlated with longevity due to increased sun exposure, and Pes et al. (2013) found that slope is advantageous by promoting increased physical activity. Both vegetation cover and gross domestic product (GDP) were found to be associated with increased longevity (Wang et al., 2015; Wang et al., 2016; Browning et al., 2019), while air pollution was considered a major threat to the health of the elderly (Wang et al., 2014; Hu et al., 2020). However, these studies of the geographical environmental factors affecting longevity were only from a self-perspective, and the spatial variability was not fully considered in the correlation analysis model. The former is due to the great difference between geographical environmental factors, so it is difficult for traditional statistical data to achieve county level comparative analysis on a national scale. Fortunately, the increasing development of remote sensing and on-the-ground monitoring networks provide the ability to construct potentially relevant variables, which are more objective and real than traditional statistical data (Mei et al., 2011; Li et al., 2017b). Part of the explanation is that the regression analysis model is out of date, and the common analysis method is to add geographical weight to the traditional ordinary least squares (OLS) model, namely, the geographically weighted regression (GWR) model (Brunsdon et al., 1996; Fotheringham et al., 2002). The GWR model assumes that all factors affect longevity on a fixed spatial scale, while multi-scale geographically weighted regression (MGWR) model has been proposed to set variable influence scales for each factor (Fotheringham et al., 2017). The MGWR model has been applied in exploratory analysis of subjects with spatial characteristics, such as epidemics and air quality (Fotheringham et al., 2019; Mansour et al., 2021), and has shown stronger fitting ability leading this approach to become an effective tool for these kinds of study as it better explains the geographical environmental factors affecting the longevity phenomenon.
To answer questions about longevity in China, this study attempts to explore the spatial distribution, gender differences and influencing factors of longevity from a geographical perspective. This study extends the existing literatures by: i) calculating the LIs at the county level across China; ii) using multisource, satellitebased remotely sensed data and on-the-ground air-monitoring data to construct independent variables of geographical environmental factors potentially affecting longevity; and iii) constructing and screening a new MGWR model for the explanation of the influence of geographical environmental factors. This paper thus aimed to uncover a more detailed characteristics of the longevity phenomenon in China, including the regional and gender differences in longevity and the geographical environmental factors that influence longevity, which could provide a scientific reference for health promotion environmental protection, and policy-making promoting longevity through economic development.

\section{Materials and methods}

\section{Study area}

Mainland China, which includes 31 provinces, excluding Hong Kong, Macao and Taiwan, as shown in Figure 1, was selected as the study area. Within this vast territory there are large natural environmental and socioeconomic differences; thus, it is often divided into four parts: eastern China, central China, western China and north-eastern China. We downloaded administrative area data from the National Geomatics Centre of China (http://ngcc.sbsm.gov.cn/), and 2838 county-level polygons were generated. These polygons represented the county level administrative units in China's administrative system, such as counties, county level cities and autonomous counties. All variables were assessed using these polygon units.

\section{Data sources}

The data used in this study included three major categories: statistical data, multisource satellite-based remotely sensed data and terrestrial air-monitored data. Statistical data included the age structure of the population derived from the Sixth Population Census of China, available from the Population Census Office of the State Council (PCOSC) and the National Bureau of Statistics of China (NBSC), which is the most systematic and informative large-scale population dataset currently available in China (PCOSC/NBSC, 2012). The multisource satellite-based remotely sensed data include digital elevation model (DEM) data, normalized difference vegetation index (NDVI) data, and night-time light data. The DEM data were obtained from the shuttle radar topography mission (STRM) dataset (https://www2.jpl.nasa.gov/srtm/). The NDVI data were downloaded from the National Aeronautics and Space Administration (NASA) in USA (https://adsweb. modaps.eosdis.nasa.gov) and batch processed with the moderate resolution imaging spectroradiometer (MODIS) reprojection tool (MRT) (Salleh et al., 2012). The night-time light data (version 4) from the DMSP/OLS sensor were obtained from the Oceanic and Atmospheric Administration (NOAA)'s National Centres for Environmental Information (https://www.ngdc. noaa.gov). We also utilized the terrestrial air-monitored data from the daily air pollution index (API) dataset for 86 key cities as published by the China Environmental Protection Ministry. All data were from 2012. 


\section{Dependent variables}

The LI was calculated based on the census data as the percentage of the population aged $>85$ to all aged $>65$, reflecting the percentage of the longevity population among the elderly population (Magnolfi et al., 2007; Wang et al., 2016). To explore the gender differences, we also calculated the LI for men and women and thus ending up with three dependent variables, i.e., the LI, the longevity index for males (LIM) and longevity index for females (LIF).

\section{Independent variables}

To explore the geographical environmental factors that influence longevity, four general geographical indexes were constructed as independent variables: the relief degree of the land surface (RDLS), NDVI, total night-time light (TNL) and API as in the following paragraphs.

\section{The relief degree of the land surface}

The RDLS index combining elevation and slope was proposed to reflect the topographical features. Based on the STRM DEM data, which were resampled to a spatial 1-km resolution, the RDLS of each pixel was calculated as the difference between the maximum and minimum elevations in a fixed square window. Previous studies showed that a $5 \times 5 \mathrm{~km}$ convolution kernel was suitable for the Chinese topographic environment (Liu et al., 2001) and was therefore adopted. Finally, we calculated the average RDLS for each county according to the administrative unit data.

\section{The normalized difference vegetation index}

The NDVI data were derived from the MOD13A3 product with a 1-km spatial resolution, which is a common geographical variable that reflects the vegetational status. It was found to be significantly correlated with the biomass and other ecological environmental indicators (Carlson and Ripley, 1997). Because the temporal resolution of the NDVI data is one month, the annual NDVI data were generated by the maximum synthesis method (Wang et al., 2018). Similar to the RDLS, the average NDVI values in each county were calculated.

\section{The total night-time light}

The TNL was defined as the number of lit pixels in each county and was calculated from the DMSP/OLS stable night-time light data with a 1-km spatial resolution. Night-time light reflects the intensity of human social activities (Elvidge et al., 2001) and recent studies indicated that there is a strong correlation between TNL and gross domestic product (GDP) (Elvidge et al., 1997; Zhu et al., 2017). Compared with the statistical GDP method, the acquisition method of TNL is more efficient and effective and the data consistency is also better (Ebener et al., 2005; Zhu et al., 2017), which is conducive to the cross-sectional comparison of counties nationwide.

\section{The air pollution index}

The API was regarded as an important geographical variable affecting longevity in this study and was processed through the following three steps: i) in the interpolation step, the ordinary Kriging spatial interpolation method was used to convert statistical data

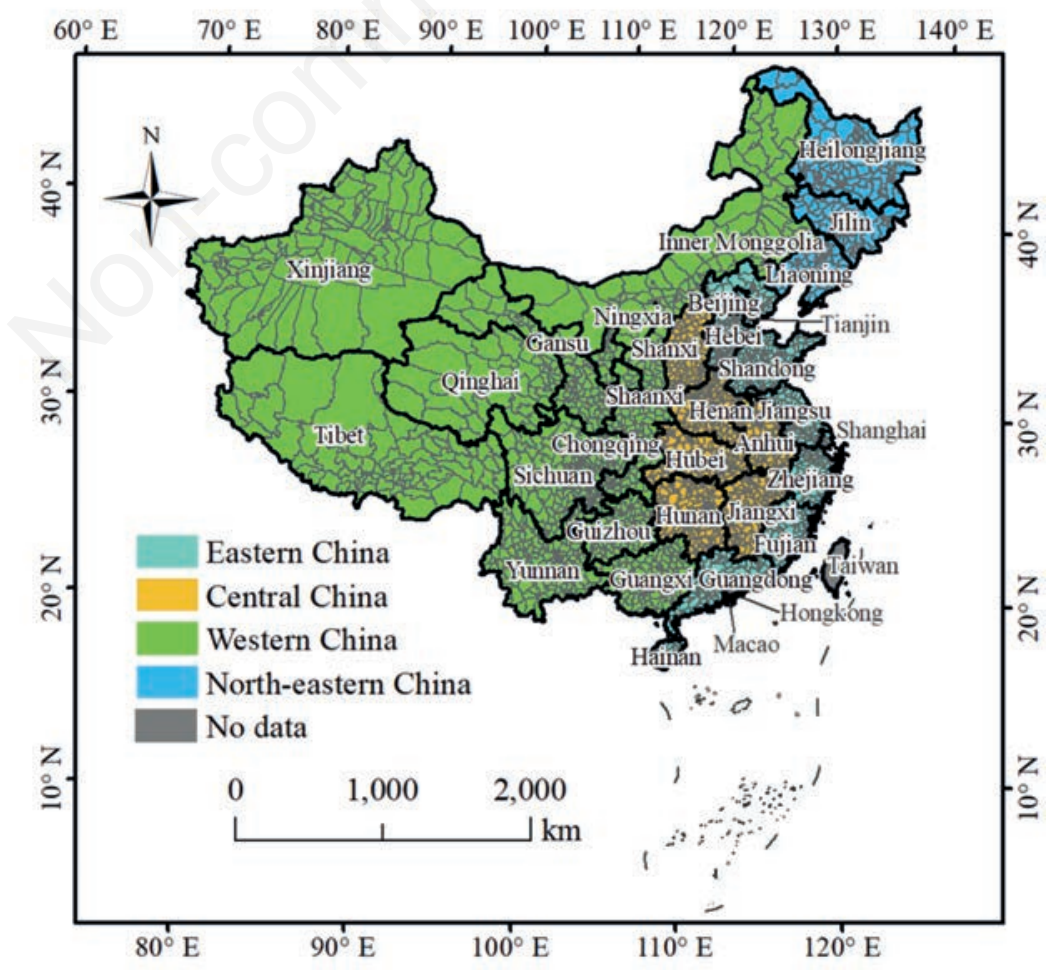

Figure 1. Study area and zones in China. 
into raster images (Li et al., 2017d; Xu et al., 2019); ii) in the synthesis step, annual average data were synthesized from the daily data; and iii) in the zonal statistics step, the average API of each county was calculated in the same way as that used for the RDLS and NDVI.

\section{Regression model}

All variables were imported into regression models to determine the influences of geographical environmental factors on longevity. To eliminate the magnitude differences and facilitate the regression calculation, four independent variables were normalized using the $z$-score method according to general practice (Brown et al., 2012; Fei et al., 2018; Gao et al., 2019) and then imported into the following three regression models to fit and compare.

\section{The ordinary least squares model}

This is a general global regression model that considers that the relationship between independent variables and dependent variables is stationary and constant and can be expressed as:

$$
y_{i}=\beta_{0}+\sum_{j=1}^{n} x_{i j} \beta_{j}+\varepsilon_{i},(i=1,2, \ldots, m ; j=1,2, \ldots, k)
$$

Where $y_{i}$ is the value of LI in the $i$-th county; $x_{i j}$ the independent variable $j$ of the $i$-th county; $\beta_{0}$ an unknown intercept; $\beta_{j}$ an unknown regression coefficient for independent variable $j$; and $\varepsilon_{i}$ the random error term.

\section{The geographically weighted regression model}

The GWR model is a spatial extension of the OLS model (Brunsdon et al., 1996), which has been widely employed in research on geography and related disciplines involving spatial pattern analysis (Li et al., 2014; Li et al., 2017b). When the centroid coordinates of each county were embedded in the regression parameters, the OLS model was extended as follows:

$$
y_{i}=\beta_{0}\left(u_{i}, v_{i}\right)+\sum_{j=1}^{n} x_{i j} \beta_{j}\left(u_{i}, v_{i}\right)+\varepsilon_{i},(i=1,2, \ldots, m ; j=1,2, \ldots, k)
$$

Where $\left(u_{i}, v_{i}\right)$ denotes the coordinates of the centroid of county $j$, with $\beta_{0}\left(u_{i}, v_{i}\right)$ and $\beta_{j}\left(u_{i}, v_{i}\right)$ denoting the intercept and local estimated coefficient of county, respectively. To simulate the interaction between neighbouring observations, a bi-square adaptive kernel function was used to calculate the spatial weight matrix between counties. This method applies a finite Gaussian regression function to assign influence values to neighbouring counties within a fixed bandwidth (Fotheringham et al., 2002). As a distance threshold, the bandwidth determines the observation objects included in the matrix, with the bandwidth usually optimized by the corrected Akaike information criterion (AICc) score (Akaike, 1981).

\section{The multi-scale geographically weighted regression model}

Recently, an MGWR was further extended on the basis of the GWR model, which allows multiple bandwidths to be generated for each independent variable (Fotheringham et al., 2017) as follows:

$$
y_{i}=\beta_{b w 0}\left(u_{i}, v_{i}\right)+\sum_{j=1}^{n} x_{i j} \beta_{b w j}\left(u_{i}, v_{i}\right)+\varepsilon_{i},(i=1,2, \ldots, m ; j=1,2, \ldots, k)
$$

Where $b w j$ denotes the bandwidth used to calibrate the $j$ th conditional relationship. MGWR uses a back-fitting algorithm for model calibration (Fotheringham et al., 2019) which is initialized with GWR parameter estimates and evaluates optimal bandwidths and locally estimated coefficients in an iterative manner (Oshan et al., 2019; Yu et al., 2019; Oshan et al., 2020). The bandwidth calibrated by the back-fitting algorithm varies with the independent variables indicating how different geographical factors affect longevity at different spatial scales and providing intuitive interpretations in terms of the affected area (Cupido et al., 2020; Harris et al., 2020). The bandwidth represents the number of counties affected by the variable, and the larger the number, the wider the influence scale of the geographical factor (Fan et al., 2020). Finally, these algorithms were initialized through the Python-based implementation of GWR and MGWR (Oshan et al., 2019).

\section{Results}

\section{Spatial distribution of the longevity index}

Using population structure data from census data, the LIs of 2838 county level polygons were calculated and a longevity map drawn as shown in Figure 2A. The LIs of all counties in China ranged from $1.3 \%$ to $16.3 \%$, and there were great regional differences. The counties with higher LI values were mainly distributed in Liaoning, Anhui, Henan, Guangxi, Sichuan, and other eastern provinces, while the counties with lower LI, such as Gansu, Inner Mongolia, and the area adjacent to the Qinghai-Tibet-Xinjiang region, were mostly distributed in western China. The spatial distribution of longevity areas in China identified by the CAGG (Figure 2B) was consistent with the LI, which verified the reliability of the LI calculated.

The $\mathrm{Hu}$ line, a famous demarcation of population density formed under resource and environmental constraints, reflects the main characteristics of population distribution in China: the eastern region is densely populated, while the western region is sparsely populated ( $\mathrm{Li}$ et al., 2017c). As shown in Figure 2A, LIs to the east of the $\mathrm{Hu}$ line were generally higher than those west of it, which indicates that longevity is influenced by resource and environmental conditions. However, the $\mathrm{Hu}$ line does not match the spatial distribution of LIs well since many counties, e.g., the counties in north-western Sichuan, eastern Tibet and southern Xinjiang, broke the trend formed by this line by having relatively poor natural and socioeconomic conditions but still exhibit a high LI. In general, compared with the population density distribution, the spatial distribution of LIs is more irregular, and the influencing factors may be more complex than what can be shown a simple line.

\section{Spatial distribution of the longevity index by gender}

Based on Figure 2C and D, we found that the longevity phenomenon showed significant gender differences by location; the LIM ranged from 0 to $13.9 \%$, and the LIF from 0 to $24.6 \%$. We compared the LIM and LIF values. Figure 3A illustrates that the percentage of females that exhibit longevity was generally higher than that of males, and counties with higher LIFs than LIMs were concentrated in eastern and central China. In contrast, some counties south of Xinjiang had higher LIMs than LIFs. Previous studies suggest that this phenomenon may be related to the local characteristics of Uyghur social life. Males are more likely to maintain a normal family status and sexual life and maintain higher levels of testosterone and oestradiol, which contribute to longevity (Zhao et al., 2003; Xu et al., 2009). The red solid line in Figure 3B shows the linear relationship between LIFs and LIMs, and the coefficient 
of determination was 0.54 indicating a significant positive correlation between them $(\mathrm{P}<0.01)$; furthermore, the intercept of 0.86 confirms that females are generally more likely to achieve longevity. The statistical results show that the LIFs were greater than the LIMs in 2614 counties (92.1\%), while the opposite situation was observed in only 224 counties $(7.9 \%)$.

\section{A LI}
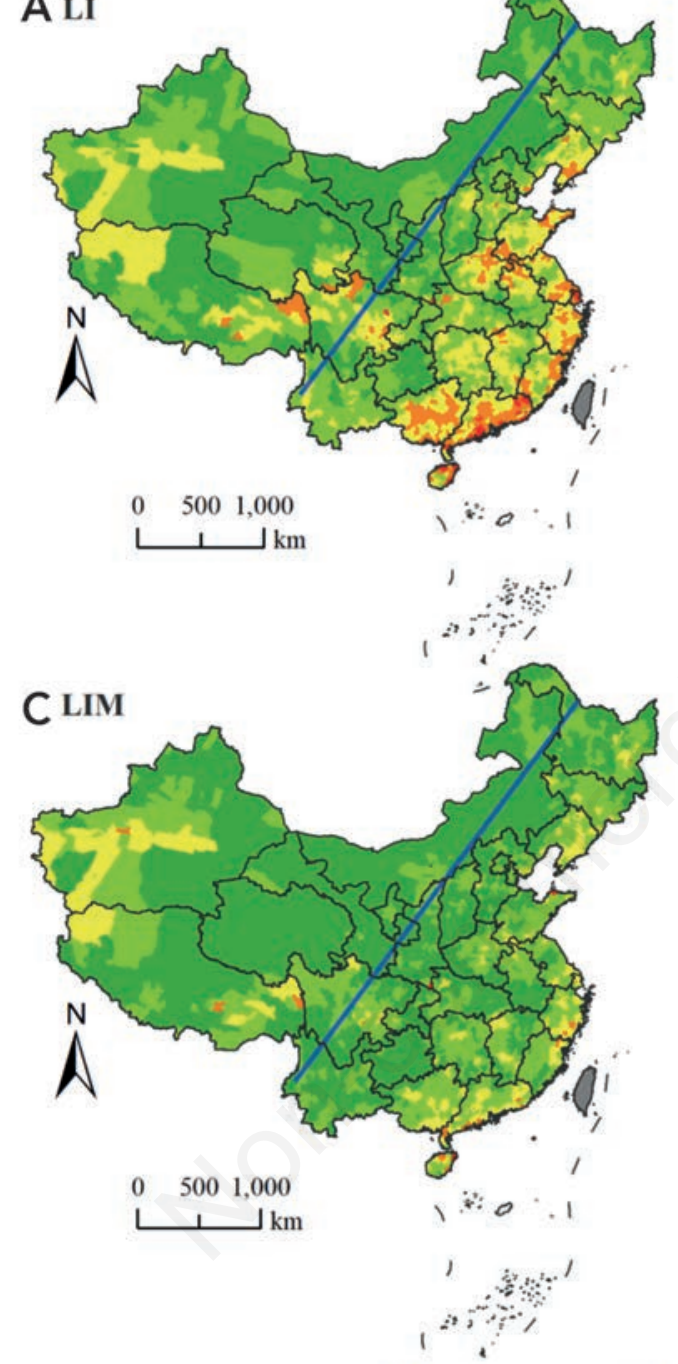

Longevity index (\%)

$0-4.5$
$4.51-6.23$

$6.24-7.97$

\section{Performance of three regression models}

First, we calculated basic statistics and performed a multicollinearity analysis for the four variables (Table 1). The variance inflation factors (VIFs) of each variable were far below 10, indicating that multicollinearity did not pose a problem. Next, two commonly used statistical parameters were used for evaluating
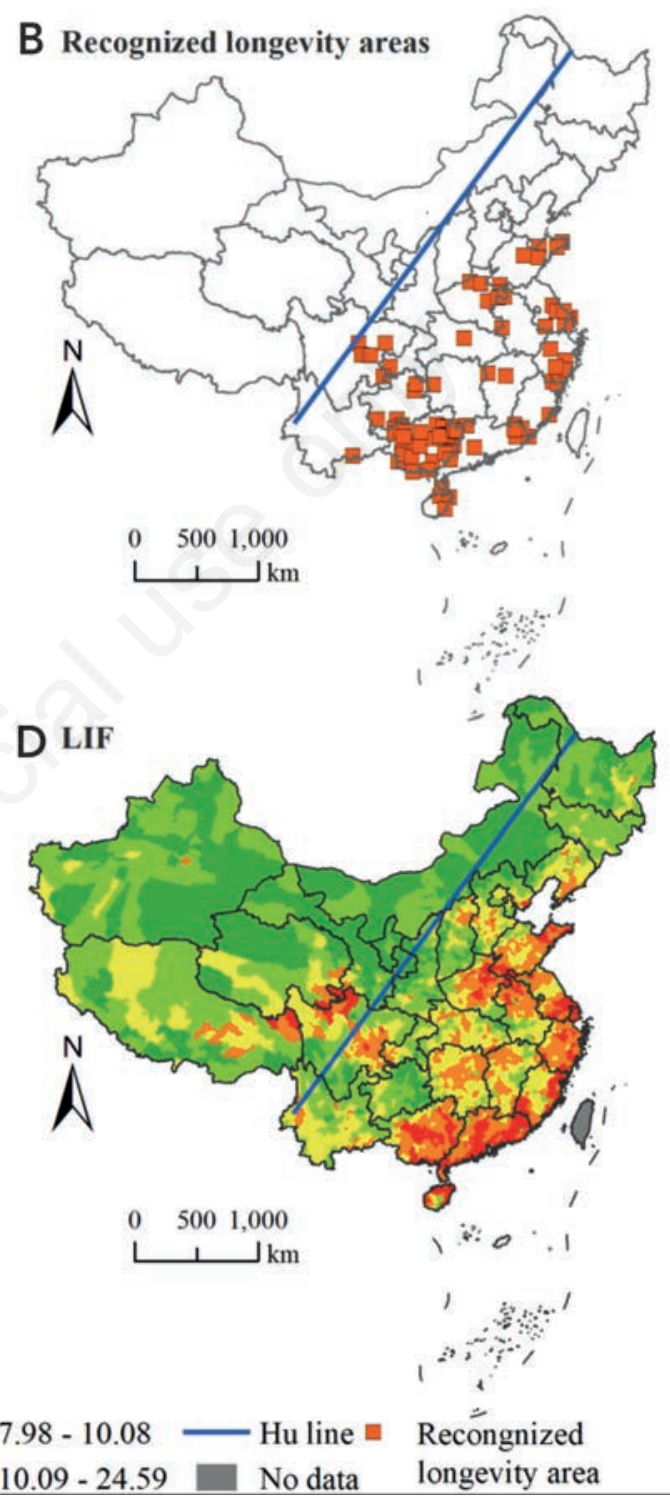

Figure 2. The spatial distributions of the three indices and recognized longevity areas in China. LI, longevity index; LIM, longevity index for males; LIF, longevity index for females.

Table 1. Descriptive statistics of independent variables.

\begin{tabular}{lccccc} 
Variable & Mean & SD & Minimum & Maximum & \\
RDLS & 258.36 & 250.88 & 4.37 & 1543.02 & 1.22 \\
NDVI & 0.68 & 0.17 & 0.07 & 0.90 & 1.04 \\
\hline TNL & 9024.85 & 8688.49 & 0.00 & 137143 & 1.13 \\
API & 68.71 & 8.49 & 40.95 & 95.99 & 1.05 \\
\hline
\end{tabular}

RDLS, relief degree of land surface; NDVI, normalized difference vegetation index; TNL, total night-time light; API, air pollution index; SD, standard deviation; VIF, variance inflation factor. 


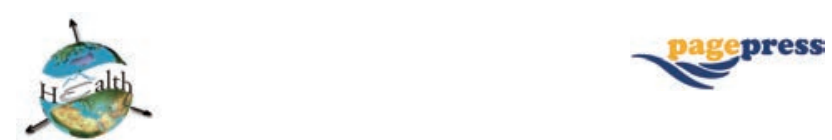

regression models, including the AICc and the adjusted $\mathrm{R}^{2}$ value (Li et al., 2017a; Fotheringham et al., 2019). When AICc is small and the adjusted $\mathrm{R}^{2}$ large, the goodness of fit of a regression model is good (Fotheringham et al., 1996). As shown in Table 2, compared with the OLS models, the performance of the GWR models was greatly improved for the three indexes. Compared with the GWR models, the MGWR models improved the overall performance with smaller AICcs. Finally, the results were statistically significant, as all values of the F-tests were much higher than the F-criterion (2.38) at a confidence level of $95 \%$.

In addition, the residuals between the observed and predicted values are also important indicators for evaluating the models ( $\mathrm{Su}$ et al., 2012). We counted all the local residuals and drew box and whisker plots (Figure 4); the residuals of OLS models showed the most discrete distribution ranges, while the distributions of residuals in the GWR models and MGWR models were more centred at approximately 0, with only slight differences between the two. Furthermore, the excellent performance of the regression model weakens the spatial autocorrelation of the residuals, as typically evaluated by Moran's I and the Monte Carlo method (Fotheringham et al., 2019). For the three indexes, the residuals of OLS, GWR and MGWR showed consistent effects for the spatial autocorrelation: the residuals of the OLS models showed significant positive spatial autocorrelations and the GWR models had markedly reduced, yet still significant spatial autocorrelations of the residuals. Only the residuals of the MGWR models exhibited a few spatial autocorrelations indicating that the regression model of the MGWR was the best (Table 3).

\section{Influence of geographical environmental factors on longevity}

According to the model outcomes and residual analysis, the performance of MGWR was better than that of GWR, while that of GWR was significantly better than that of OLS. Due to the performance results, we used only the results of MGWR models to investigate the influences of geographical environmental factors on longevity; all the local coefficients and their significance results (ttest; $\mathrm{P}<0.05$ ) are displayed in Figure 5 , and the numbers of counties with significant positive and negative relations between LI and geographical variables are shown in Figure 6.

Figure 5A illustrates the spatial distribution of local parameter estimates associated with RDLS, which varies from north to south. RDLS was significantly positively correlated with LI in 295 counties $(10.4 \%)$ but significantly negatively correlated with LI in 1708 counties $(60.2 \%)$ (Figure 6$)$. The positive correlations were mainly
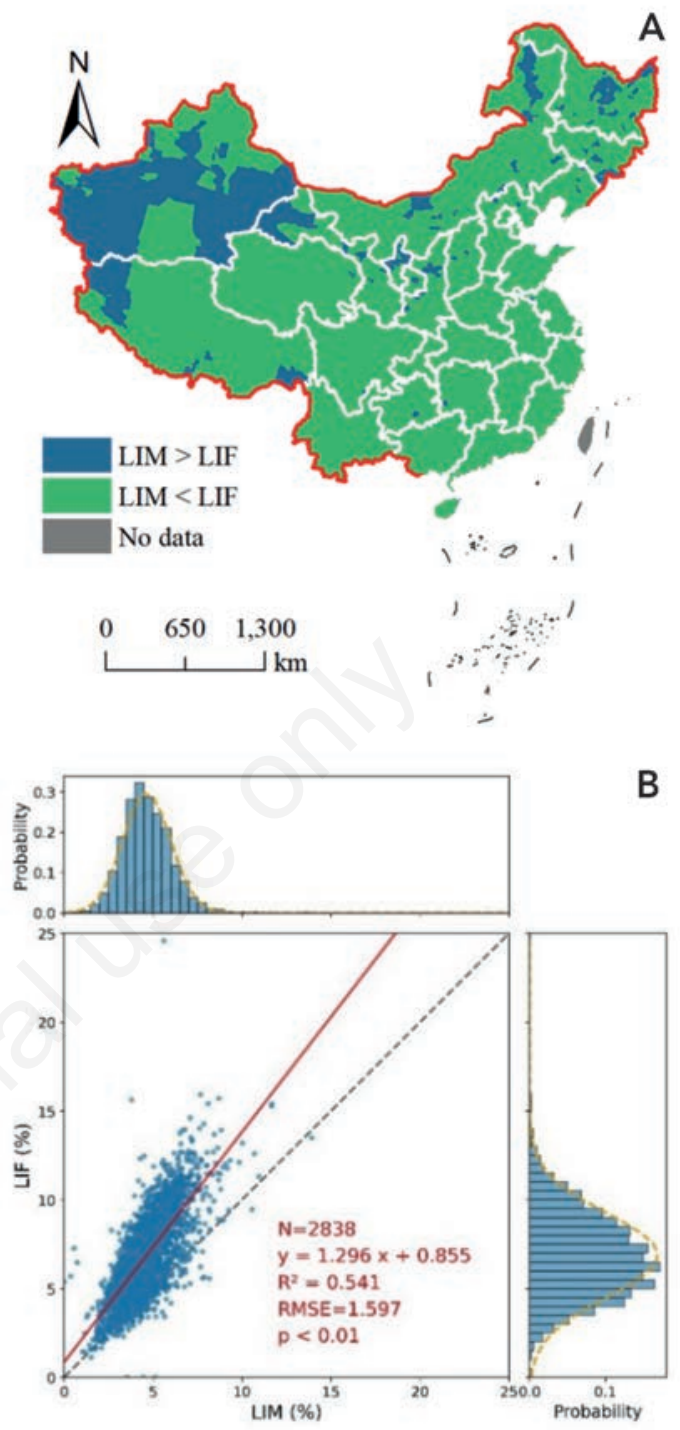

Figure 3. Comparison between different genders. A) The spatial distribution of the longevity index for males (LIM) and longevity index for females (LIF) areas; B) scatter plot and probability distribution histograms of LIM and LIF. RMSE, root mean squared error.

Table 2. Performance of the three models with respect to different indexes.

\begin{tabular}{lcccc} 
Model & Index & AlCc & $\begin{array}{c}\text { Model performance } \\
\text { Adjusted R }\end{array}$ & F-test \\
OLS & LI & 10566.36 & 0.23 & 206.54 \\
GWR & LI & 7979.36 & 0.76 & 2615.00 \\
\hline MGWR & LI & 7778.13 & 0.76 & 2464.03 \\
OLS & LIM & 9251.17 & 0.15 & 125.49 \\
\hline GWR & LIM & 7313.70 & 0.67 & 1641.97 \\
MGWR & LIM & 7158.21 & 0.66 & 1462.64 \\
\hline OLS & LIF & 12152.05 & 0.24 & 223.61 \\
GWR & LIF & 9310.74 & 0.77 & 2704.36 \\
\hline MGWR & LIF & 9060.65 & 0.79 & 2967.18 \\
\hline
\end{tabular}

OLS, ordinary least squares; GWR, geographically weighted regression; MGWR, multi-scale geographically weighted regression; LI, longevity index; LIM, longevity index for males; LIF, longevity index for females; Fcriterion, 2.38 at the $5 \%$ significance level. 
distributed in north-eastern China, while the negative correlations were mainly distributed in the South. These distributions may be related to the physical activities of the local people. In north-eastern China, which is a low-lying and cold region, where more activity is needed to remain healthy, while in the humid, mountainous area of the Southwest, the complex terrain is a threat to the health of the local people. Additionally, the optimized bandwidth of RDLS includes 148 nearest neighbours, indicating that RDLS affected LI at the regional scale.

Figure $5 \mathrm{~B}$ shows the spatial distribution of local parameter estimates associated with NDVI. The optimized bandwidth of NDVI included 195 nearest neighbours, which is a wide measure indicating a broad influence. NDVI was significantly positively associated with LI in 888 counties (37.3\%), while the opposite was true in 490 counties (17.3\%) (Figure 6). In Xinjiang, Tibet, Qinghai, and Henan, the local coefficients of NDVI were found to be positive indicating that the improvement of the ecological environment in these counties helps to improve the LI, while they were negative in Guizhou and Beijing. This result may be related to the stronger ecological carrying capacity of these counties ( $\mathrm{Xu}$ et al., 2010), for which a higher NDVI also represents lower economic and medical standards.

Figure $5 \mathrm{C}$ presents the spatial distribution of the local parameter estimates associated with TNL, which was found to vary from west to east. The optimized bandwidth of TNL included 324 nearest neighbours, which was the widest measure found, indicating that TNL affected the LI at very wide range. TNL positively and significantly affected the LI in 991 counties (34.9\%) (Figure 6), and these counties were mainly located in Hainan, Zhejiang, with also some provinces in eastern China. In contrast, TNL negatively and significantly affected the LI in 456 counties (16.1\%) (Figure 6 ), with the countries mainly distributed in Xinjiang, Qinghai and some provinces in western China. In general, except for western China, which has poor ecological productivity (Yang et al., 2018), the economic development represented by TNL could help people achieve longevity.

Figure 5D illustrates the spatial distribution of local parameter estimates associated with the API. The optimized bandwidth of the API included only 20 nearest neighbours, which indicates that API generation and diffusion are complex and affect the LI at the local scale (Xu et al., 2019). As a result, counties whose LI was significantly related to API were scattered. The numbers (proportions) of counties with significant positive and negative correlations between the API and the LI were 875 (30.8\%) and 668 (23.5\%), respectively (Figure 6). In the initial stage of regional economic
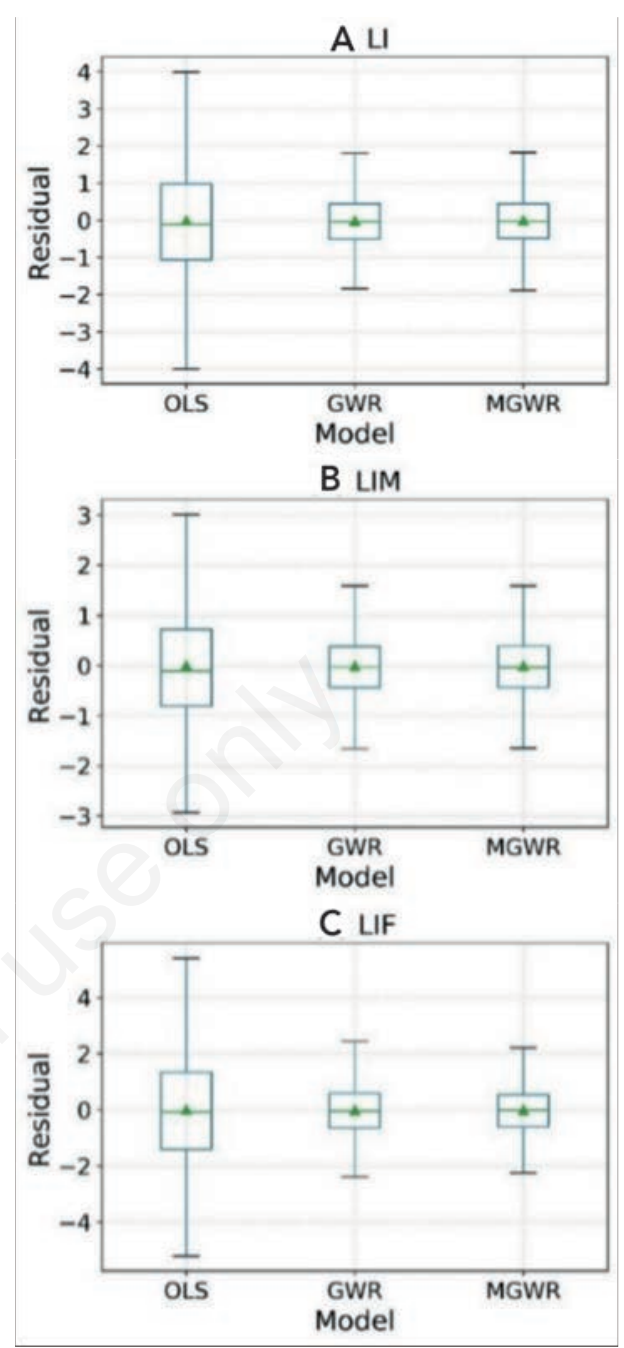

Figure 4. Box and whisker plots of the residual distribution output from the three models for the three indices: A) longevity index (LI); B) longevity index for males (LIM); C) and longevity index for females (LIF). The boxes show the interquartile range (25\%-75\%), with the medians and means marked by green horizontal lines and small triangles in each box. The whiskers illustrate the range of three indices. OLS, ordinary least squares; GWR, geographically weighted regression; MGWR, multi-scale geographically weighted regression.

Table 3. Spatial autocorrelation analysis of the residuals of the three models.

\begin{tabular}{lcccc} 
Model & Index & Moran's I & $\begin{array}{c}\text { Residual autocorrelation of the models } \\
\text { Z-score }\end{array}$ & $\begin{array}{c}\text { P-value } \\
\text { OLS }\end{array}$ \\
GWR & LI & $0.67^{*}$ & 49.45 & 0.01 \\
\hline MGWR & LI & $0.06^{*}$ & 5.07 & 0.01 \\
OLS & LI & 0.01 & 0.35 & 0.35 \\
\hline GWR & LIM & $0.58^{*}$ & 50.71 & 0.01 \\
MGWR & LIM & $0.03^{*}$ & 2.65 & 0.01 \\
\hline OLS & LIM & -0.01 & -1.08 & 0.14 \\
GWR & LIF & $0.69^{*}$ & 52.07 & 0.01 \\
\hline MGWR & LIF & $0.09^{*}$ & 7.81 & 0.01 \\
\hline
\end{tabular}

OLS, ordinary least squares; GWR, geographically weighted regression; MGWR, multi-scale geographically weighted regression; LI, longevity index; LIM, longevity index for males; LIF, longevity index for females. *Correlation significant at the $5 \%$ level. 
development, air pollution is almost inevitable; thus, the API may show a positive correlation with the LI (Wang et al., 2014), but this does not mean that air pollution is conducive to longevity.

\section{Gender differences in geographical environmental influence}

The regression results of the MGWR models for LIM and LIF are shown in Figures 7 and 8, respectively. To facilitate the comparison of the influence of geographical environmental factors by gender, we divided the positive and negative influences to count the number of counties with significant correlations between the two indices and geographical variables (Figure 9). On this basis, we summarized three types of attributes: male-friendly factors, female-friendly factors, and non-gender-biased factors.

Both RDLS and API are male-friendly factors. In terms of the positive influences of RDLS and API, there were more counties for which the LIM was significantly affected (635 and 917, respective- ly) than there were counties for which the LIF was significantly affected (153 and 782, respectively) (Figure 9). However, regarding the negative influence of RDLS and API, there were fewer counties in which the LIM was significantly affected ( 0 and 413, respectively) than there were counties in which the LIF was significantly affected (1478 and 712, respectively) (Figure 9). In terms of spatial distribution, the positive influence of RDLS on males was mainly manifested in south-eastern China (Figure 7A), while the negative influence of RDLS on females was mainly manifested in the south-western part of the country (Figure 8A). Furthermore, the gender differences in the API were relatively small, and the distribution was scattered.

NDVI is a female-friendly factor. NDVI was significantly positively correlated with the LIF in 888 counties, while the LIM was significantly positively correlated in only 317 counties (Figure 9A). However, NDVI was significantly negatively correlated with the LIM in 1127 counties, while only 24 counties were significant-
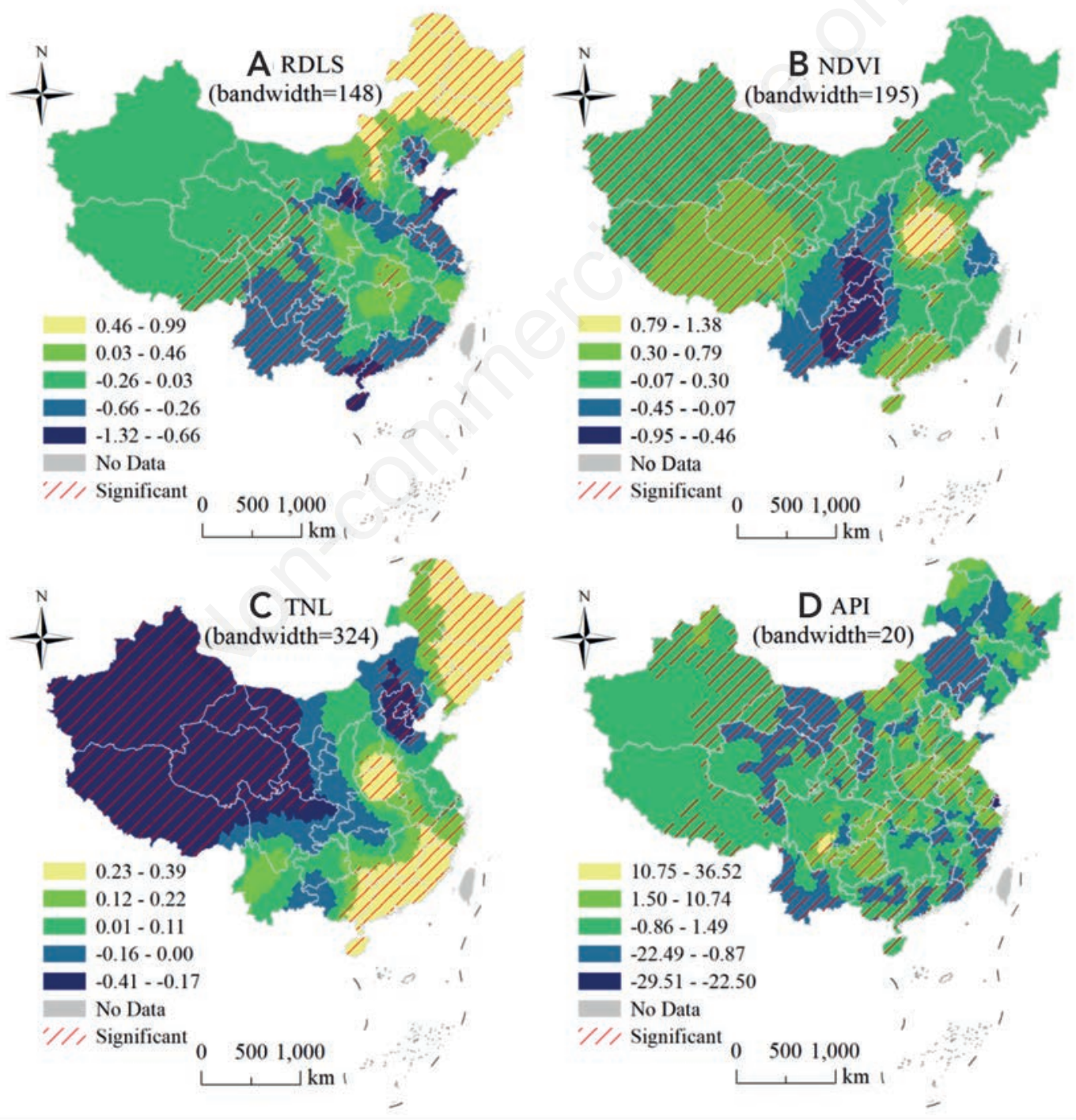

Figure 5. The spatial distribution and significance of local multi-scale geographically weighted regression model coefficients between longevity index and geographical variables: A) relief degree of the land surface (RDLS); B) normalized difference vegetation index (NDVI); C) total night-time light (TNL); D) air pollution index (API). 
ly negatively correlated with the LIF (Figure 9B). In terms of spatial distribution, a female-friendly influence of NDVI was mainly manifested in Guangdong, Hainan, and Qinghai (Figure 8B), and the negative influence of NDVI on males was mainly manifested in south-western China (Figure 7B).

TNL is the only non-gender-biased factor for longevity. TNL had a significant positive correlation with LIF in many counties (Figure 9A) and a significant negative correlation with LIF in many counties (Figure 9B). Regardless of whether it was positive or negative, the influence of TNL on the longevity of females was always stronger than that on males and it did not show a gender bias. In terms of spatial distribution, compared to the LIM, there were more counties with significant positive and negative influences of TNL on the LIF. The spatial patterns included the negative influences in western China and the positive influences in some counties in Zhejiang, Henan, and so on (Figure 8C).

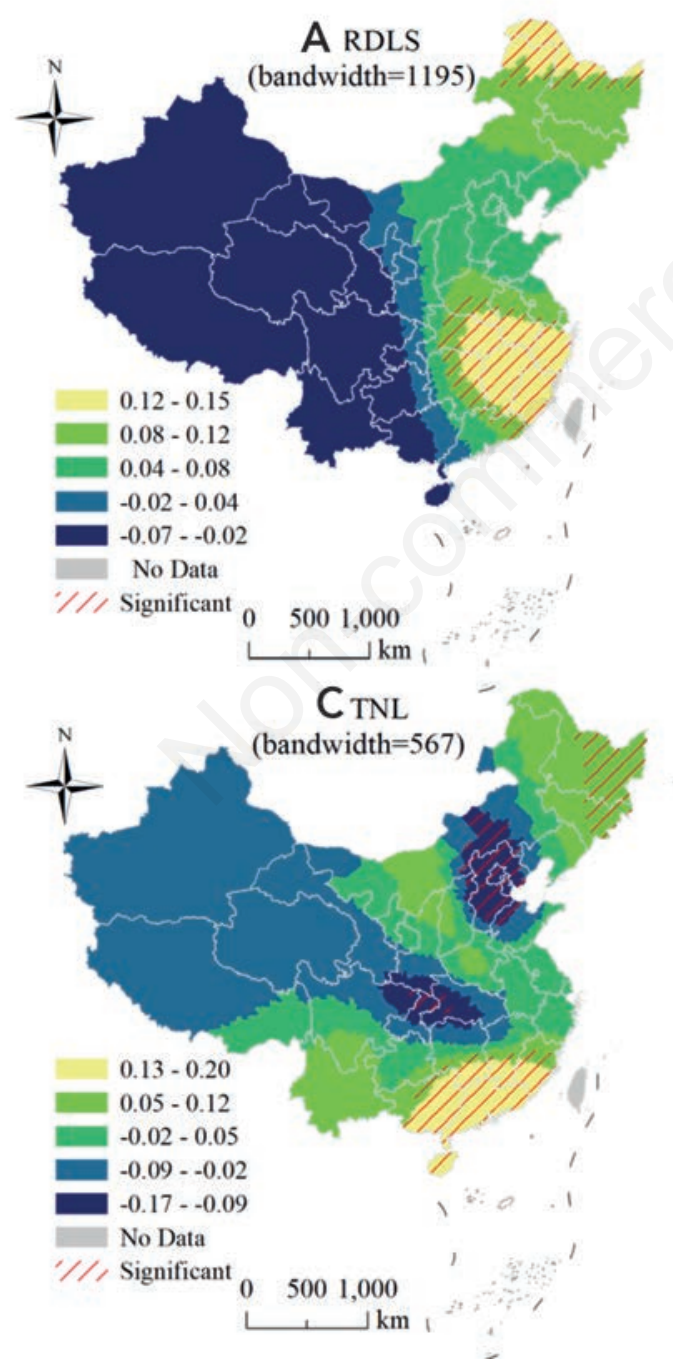

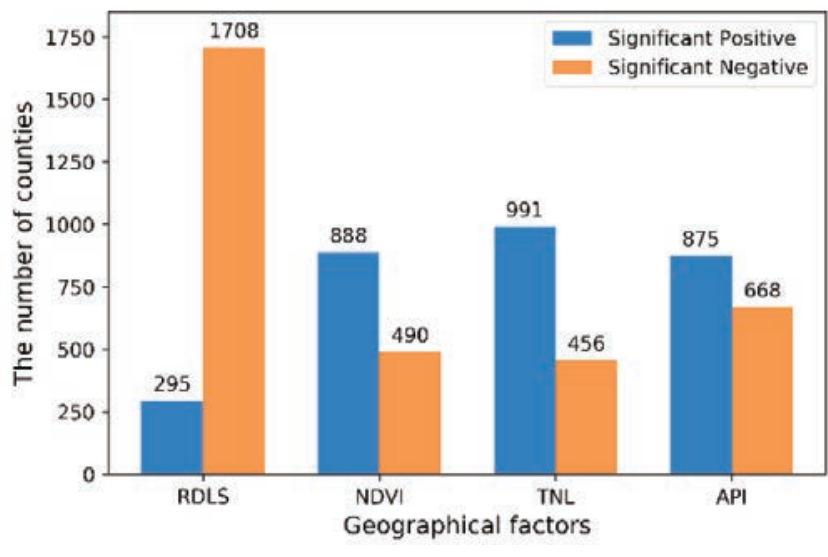

Figure 6. Counties with significant local parameter estimates. RDLS, relief degree of the land surface; NDVI, normalized difference vegetation index; TNL, total night-time light; API, air pollution index.

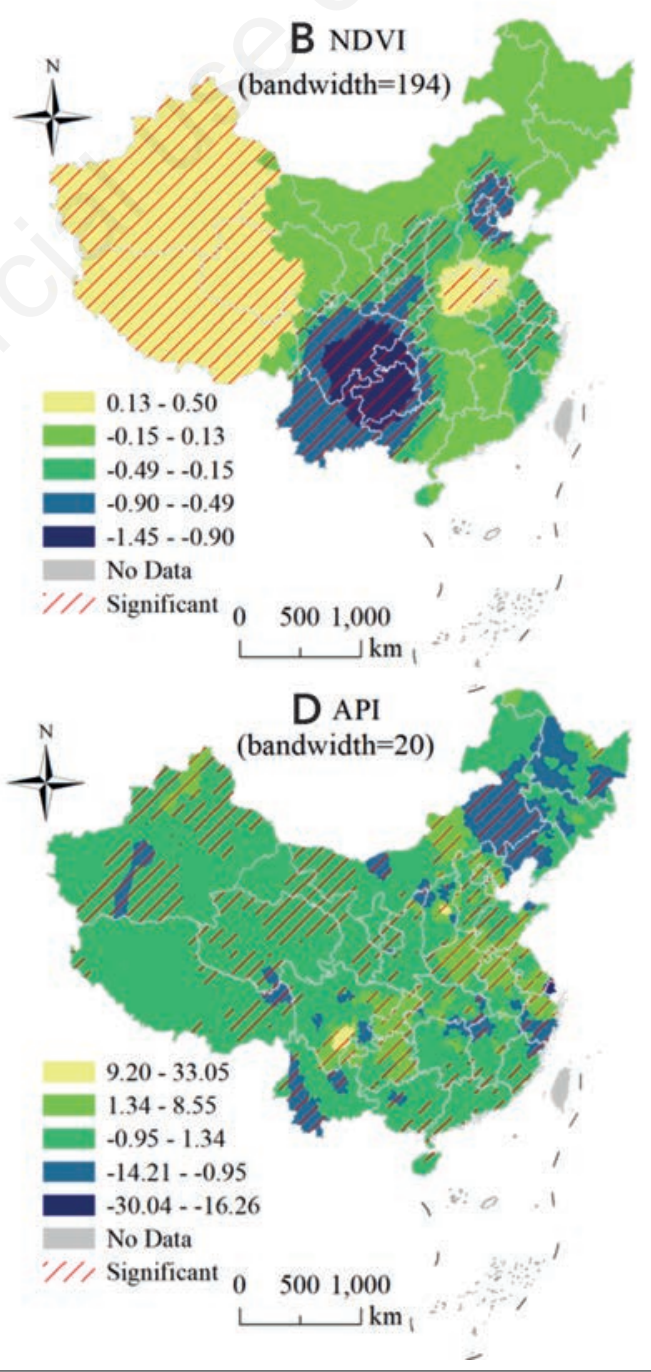

Figure 7. The spatial distribution and significance of local multi-scale geographically weighted regression model coefficients between longevity index for males and geographical variables: A) relief degree of the land surface (RDLS); B) normalized difference vegetation index (NDVI); C) total night-time light (TNL); D) air pollution index (API). 


\section{Discussion}

Most studies have explained the longevity phenomenon at the individual level and the influencing factors found include heredity (Ljungquist et al., 1998; Vaupel et al., 1998), disease (Candore et al., 2010; Spann and Ottinger, 2018), psychology (Giorgio et al., 2016), etc. However, these findings are inadequate to explain the public health implications of longevity at the regional level. Especially in the large territory of China as a whole, the longevity of individuals varies greatly from region to region, and the few studies that have been conducted at the provincial level or in typical cities are generally too vague due to the use of traditional statistical data and analytical methods. To fill this gap, we investigated the spatial distribution and gender differences in longevity at the county level, as well as the impacts of topographic features, vegetation conditions, human social activity and air pollution factors from a geographical perspective with the support of new data and regression models.
In China, the spatial distribution and gender characteristics of longevity show regional differences. The results showed that the LIs of all counties in China ranged between $1.3 \%$ and $16.3 \%$ and presented an overall spatial pattern that was high in the East and low in the West. Where census data were available, the LIs of this study were calculated based on the percentage of the elderly population that was over 85 years old rather than the usual percentage of nonagenarians. The calculation results were similar to those of recognized longevity areas and previous studies (Lv et al., 2011; Song et al., 2016). Expanding on previous studies, more detailed county level LIs were obtained and mapped, which provide the possibility to further explore the geographical factors and gender differences with respect to longevity. In addition, differences in life expectancy by gender occur in many areas, and it is known that females tend to live longer (Zhang and Wei, 2016; Liu et al., 2019; Zafeiris, 2020). Differences in longevity by gender were found in this study and they were similar to those shown by life expectancy. Females had an advantage over males, as the LIF was greater than
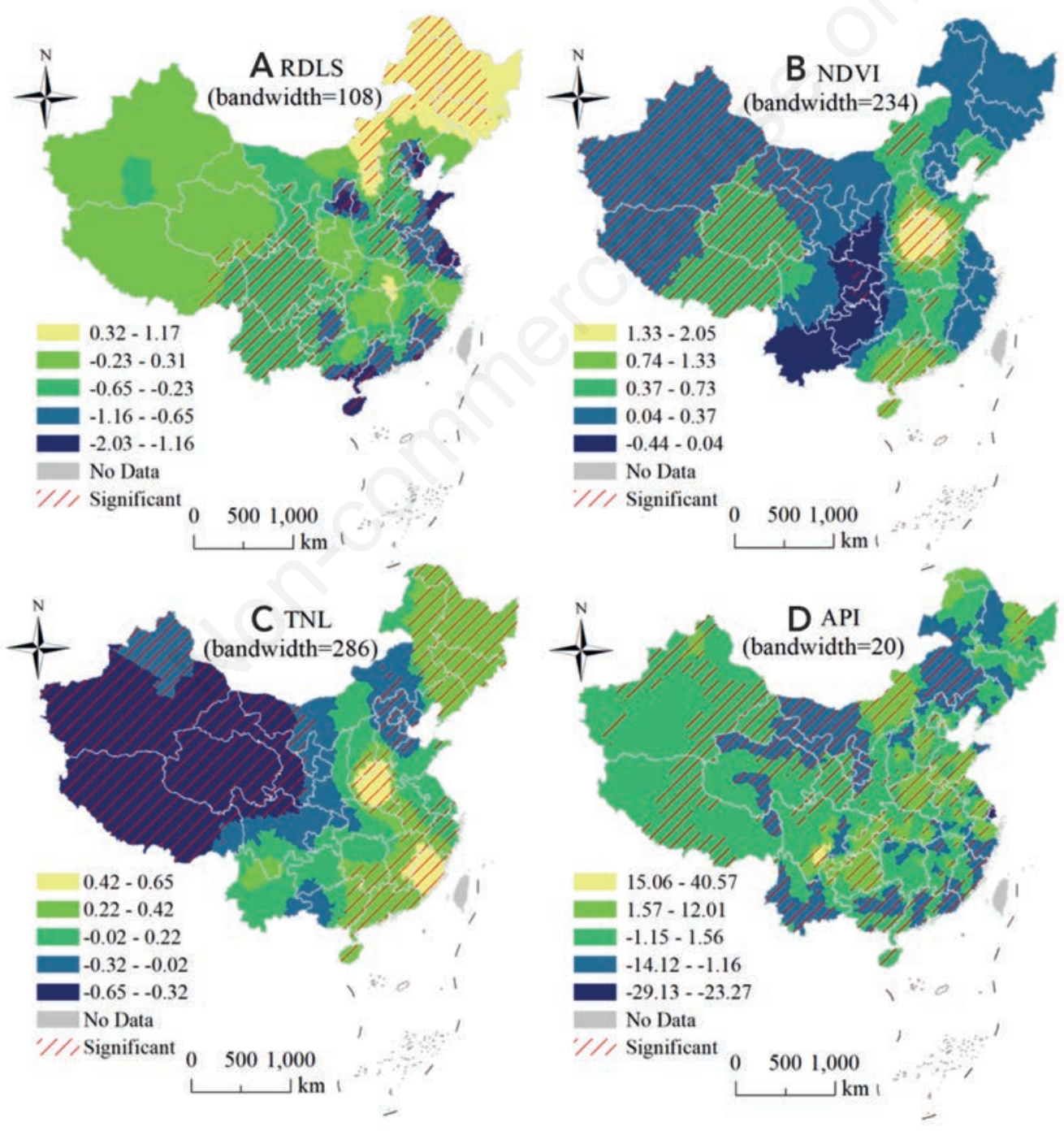

Figure 8. The spatial distribution and significance of local multi-scale geographically weighted regression model coefficients between longevity index for females and geographical variables: A) relief degree of the land surface (RDLS); B) normalized difference vegetation index (NDVI); C) total night-time light (TNL); D) air pollution index (API). 
the LIM in 2614 counties (92.1\%); however, the LIM was higher in the other 224 counties $(7.9 \%)$.

Furthermore, spatial variation in the geographical environmental factors affecting longevity was found. Using multisource, satellite-generated, remotely sensed data and terrestrial air-monitored data, four indices related to general geographical factors were innovatively constructed as independent variables and imported into the traditional OLS model, the common GWR model and the new MGWR model. Once again, this study proved that the GWR model is better than the traditional OLS model for the regression of spatial data ( $\mathrm{Su}$ et al., 2012; Li et al., 2017a), but it is impractical to set a fixed bandwidth for all independent variables in GWR. In general, variables have different influence ranges; that is, they affected the dependent variable at different spatial scales, and the MGWR model was proposed to account for this (Fotheringham et al., 2017). According to statistical results, including AICc, adjusted $\mathrm{R}^{2}$, and the F-test, the three models can be ranked in terms of performance from OLS via GWR to MGWR on a good to better scale. From the analysis of the ability of the models to alleviate the residuals, Moran's I was innovatively used to evaluate the spatial autocorrelation of residuals, and the performance on a scale from good to better was again OLS via GWR to MGWR. In particular, the low spatial autocorrelation (the absolute value of Moran's $I<0.02$ ) and non-significance $(\mathrm{P}>0.1)$ residuals validated the superiority of MGWR by setting the multi-scale bandwidth for different independent variables. Therefore, the MGWR results were analysed, and it was revealed that there was variability in the influential factors. One is the scale variability: different geographical environmental factors affected longevity at variable spatial scales, so their bandwidths in the MGWR models were different (Fotheringham et al., 2017). The spatial scale rankings of the four geographical factors on longevity were as follows: TNL $>$ NDVI $>$ RDLS $>$ API. Another is the spatial variability: the influence of geographical environmental factors on longevity was not fixed and demonstrated variable effects in different regions. For example, increasing the TNL in eastern China means economic growth, which can help develop medical care and improve the LI, but doing so in western China could backfire because economic development may damage the environment in the ecologically fragile western part of the country and produce the opposite result. In the process of affecting longevity, the scale variability and spatial variability shown by the factors conform to geographical patterns, which are widely found in the formation of subjects with spatial attributes, such as air pollutants and epidemic diseases (Xu et al., 2019; Ballard and Bone, 2021). However, it is worth noting that the factors affecting the longevity differently in the two genders also varied. On the one hand, the bandwidths acting on them were not fixed illustrating that the influence of geographical environmental factors on the longevity of females and males occurs at different spatial scales. For females, the smaller bandwidth produced by RDLS and TNL means that these factors influenced the longevity probability over a smaller spatial range, while the larger bandwidth produced by NDVI means that ecological quality impacted the longevity probability over a larger spatial range. On the other hand, similar to the effects on the LI, the influence of geographical environmental factors on the LIM and the LIF also exhibited spatial variability. Based on the statistical results of counties, whose longevity was significantly affected by geographical environmental factors, this study described RDLS and API as female-friendly, NDVI as malefriendly and TNL as non-biased by gender.

The findings discussed above are important for those concerned about the variable relationship between longevity and geographical environmental factors as they provide scientific refer- ences for health promotion, environmental protection and economic development policy-making regarding longevity. For example, regarding the criteria and methods for recognizing longevity areas, the following three suggestions were put forward to the CAGG: i) more geographical data and analysis models should be considered in the recognition methods. Large-scale, multisource, satellite-generated, remotely sensed data and terrestrial air-monitored data are more realistic and easier to organize than the traditional statistical data, and the geographical model represented by MGWR is able to meet the needs of exploratory analysis; ii) more attention should be given to the geographical environment, and the weight of geographical environmental factors should be increased in the recognition criteria of longevity areas. In the current indicator system, the three core indices on population structure account for $60 \%$ of the weight, while geographically related indicators such as forest coverage, air quality and economic income do not exceed 5\% (CAGG, 2019). People's attention to longevity areas involves pursuing an environment that produces natural longevity phenomena rather than being curious about the proportion of the long-lived population. This is why urban centres where many elderly people gather have maintained a high longevity ratio, but they still cannot be called longevity areas; iii) attention should be paid to the variability in longevity, including the variability in geographic factors
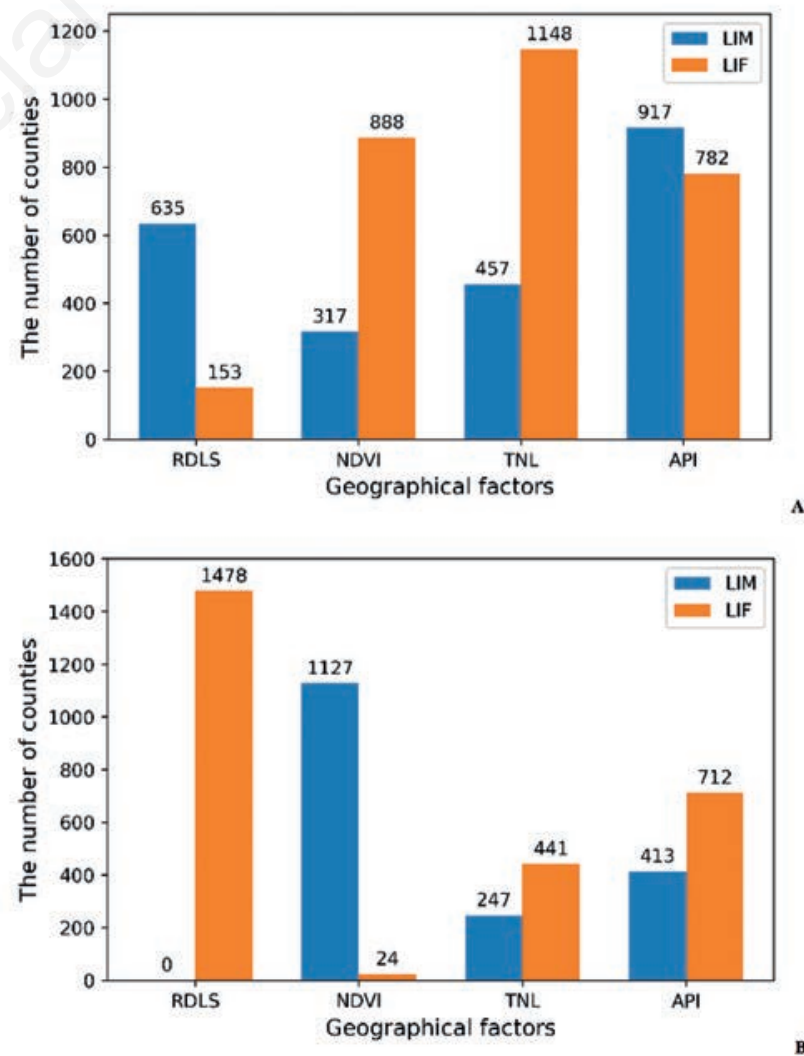

Figure 9. Statistics of counties with significant positive and negative local parameter estimates. A) Significant positive influence; B) significant negative influence. RDLS, relief degree of the land surface; NDVI, normalized difference vegetation index; TNL, total night-time light; API, air pollution index; LIM, longevity index for males; LIF, longevity index for females. 
and gender differences and adaptive evaluation standards should be implemented in different types of areas. All counties west of the $\mathrm{Hu}$ line in China have not been recognized, including counties in southern Xinjiang that have been recognized by the International Natural Medicine Society (INMS) as the world's fourth longevity region (Liu et al., 2014) because static indices such as forest coverage and economic level in the current indicator system were unfavourable to them.

There are several limitations in this study and the main challenge is to make a general conclusion without individual data. The effects and mechanisms of geographical environmental factors acting on long-lived individuals need to be further verified. In the future, the experimental data of this study should be enriched and integrated with individual data from Guangxi, Xinjiang and other recognized longevity areas based on the seventh census data (State Council of China, 2019) and various remotely sensed data to improve fitting performance and persuasion. Additionally, although remotely sensed data since the 1990 s are easy to obtain and organize allowing multiple geographic factor variables to be constructed on a large scale (Xie et al., 2019; Li et al., 2021), their uncertainty is also a focus worthy of further research (Wu et al., 2019).

\section{Conclusions}

The main contribution of this study is the finding that the spatial distribution, gender differences and influencing factors of the longevity phenomenon all exhibit obvious spatial heterogeneity. By constructing three longevity indices, the longevity phenomenon and its gender differences at the county level can be visualized on a map, which enriches our knowledge of where people tend to live longer. Supported by multisource, satellite-based remotely sensed data, terrestrial air-monitored data and the MGWR model, this study explored the relationship between longevity and topographic features, vegetation conditions, human social activity and air pollution from a geographical perspective. The superiority of the MGWR model was proven, and the effects of geographical environmental factors on longevity were found to vary. These findings enrich our understanding of the geographical environment of longevity in China. It will serve as an important reference regarding the variation in longevity and environmental factors for decision-makers during the formulation of suitable policies for simultaneously facilitating human health, environmental protection, and economic development.

\section{References}

Akaike H, 1981. Likelihood of a model and information criteria. J Econom 16:3-14.

Ballard K, Bone C, 2021. Exploring spatially varying relationships between Lyme disease and land cover with geographically weighted regression. Appl Geogr 127:102383.

Brown S, Versace VL, Laurenson L, Ierodiaconou D, Fawcett J, Salzman S, 2012. Assessment of spatiotemporal varying relationships between rainfall, land cover and surface water area using geographically weighted regression. Environ Model Assess 17:241-54.

Browning MHEM, Lee K, Wolf KL, 2019. Tree cover shows an inverse relationship with depressive symptoms in elderly residents living in U.S. nursing homes. Urban For Urban Gree
41:23-32.

Brunsdon C, Fotheringham AS, Charlton ME, 1996. Geographically weighted regression: a method for exploring spatial nonstationarity. Geogr Anal 28:281-98.

CAGG, 2019. Criteria and methods for recognizing longevity area. Available from: http://www.cagg.org.cn/portal/page/index/ id/13.html Accessed: 20 March 2021.

CAGG, 2021. China Association of Gerontology and Geriatrics. Available from: http://www.cagg.org.cn Accessed: 20 March 2021.

Candore G, Balistreri CR, Colonna-Romano G, Lio D, Listi F, Vasto S, Caruso C, 2010. Gender-related immune-inflammatory factors, age-related diseases, and longevity. Rejuv Res 13:292-7.

Carlson TN, Ripley DA, 1997. On the relation between NDVI, fractional vegetation cover, and leaf area index. Remote Sens Environ 62:241-52.

Chrysohoou C, Skoumas J, Pitsavos C, Masoura C, Siasos G, Galiatsatos N, Psaltopoulou T, Mylonakis C, Margazas A, Kyvelou S, Mamatas S, Panagiotakos D, Stefanadis C, 2011. Long-term adherence to the Mediterranean diet reduces the prevalence of hyperuricaemia in elderly individuals, without known cardiovascular disease: The Ikaria study. Maturitas 70:58-64.

Cupido K, Fotheringham AS, Jevtic P, 2020. Local modelling of US mortality rates: a multiscale geographically weighted regression approach. Popul Space Place: 1-28.

Ebener S, Murray C, Tandon A, Elvidge CC, 2005. From wealth to health: modelling the distribution of income per capita at the sub-national level using night-time light imagery. Int J Health Geogr 4:1-17.

Elvidge CD, Baugh KE, Kihn EA, Kroehl HW, Davis ER, Davis CW, 1997. Relation between satellite observed visible-near infrared emissions, population, economic activity and electric power consumption. Int J Remote Sens 18:1373-9.

Elvidge CD, Imhoff ML, Baugh KE, Hobson VR, Nelson I, Safran J, Dietz JB, Tuttle BT, 2001. Night-time lights of the world: 1994-1995. Isprs J Photogramm 56:81-99.

Fan ZY, Zhan QM, Yang C, Liu HM, Zhan M, 2020. How did distribution patterns of particulate matter air pollution (PM(2.5)and PM10) change in China during the COVID-19 Outbreak: A spatiotemporal investigation at Chinese city-level. Int J Environ Res Public Health 17:6274.

Fei XF, Chen WZ, Zhang SQ, Liu QM, Zhang ZH, Pei Q, 2018. The spatio-temporal distribution and risk factors of thyroid cancer during rapid urbanization-A case study in China. Sci Total Environ 630:1436-45.

Fotheringham AS, Brunsdon CF, Charlton ME, 2002. Geographically weighted regression: The analysis of apatially varying relationships. Wiley, New York, NY, USA.

Fotheringham AS, Charlton M, Brunsdon C, 1996. The geography of parameter space: An investigation of spatial non-stationarity. Int J Geogr Inf Syst 10:605-27.

Fotheringham AS, Yang WB, Kang W, 2017. Multiscale geographically weighted regression (MGWR). Ann Am Assoc Geogr 107:1247-65.

Fotheringham AS, Yue H, Li ZQ, 2019. Examining the influences of air quality in China's cities using multi-scale geographically weighted regression. T Gis 23:1444-64.

Gao JB, Jiao KW, Wu SH, 2019. Revealing the climatic impacts on spatial heterogeneity of NDVI in China during 1982-2013. Acta Geograph Sinica 74:534-43.

Giorgio M, Renzi C, Oliveri S, Pravettoni G, 2016. Maternal care 
determinant of longevity? Arch Ital Biol 154:14-25.

Harris P, Lanfranco B, Lu BB, Comber A, 2020. Influence of geographical effects in hedonic pricing models for grass-fed cattle in Uruguay. Agriculture-Basel 10.

Hu K, Keenan K, Hale JM, Borger T, 2020. The association between city-level air pollution and frailty among the elderly population in China. Health Place 64.

Jia P, Lakerveld J, Wu J, Stein A, Root E, Sabel C, Vermeulen R, Remais J, Chen X, Brownson R, Amer S, Xiao Q, Wang L, Verschuren M, Wu T, Wang Y, James P, 2019. Top 10 research priorities in spatial lifecourse epidemiology. Environ Health Persp 127:74501.

Jia P, Yu C, Remais J, Stein A, Liu Y, Brownson R, Lakerveld J, Wu T, Yang L, Smith M, Amer S, Pearce J, Kestens Y, Kwan M, Lai S, Xu F, Chen X, Rundle A, Xiao Q, Xue H, Luo M, Zhao L, Cheng G, Yang S, Zhou X, Li Y, Panter J, Kingham S, Jones A, Johnson B, Shi X, Zhang L, Wang L, Wu J, Mavoa S, Mwenda K, Wang Y, Verschuren M, Vermeulen R, James P, 2020. Spatial lifecourse epidemiology reporting standards (ISLE-ReSt) statement. Health Place 61:102243.

Johnson O, Diggle P, Giorgi E, 2020. Dealing with spatial misalignment to model the relationship between deprivation and life expectancy: a model-based geostatistical approach. Int J Health Geograph 19.

Li C, Li FB, Wu ZF, Cheng J, 2017a. Exploring spatially varying and scale-dependent relationships between soil contamination and landscape patterns using geographically weighted regression. Appl Geogr 82:101-14.

Li H, Wei YD, Zhou Y, 2017b. Spatiotemporal analysis of land development in transitional China. Habitat Int 67:79-95.

Li J, Lu D, Xu C, Li Y, Chen M, 2017c. Spatial heterogeneity and its changes of population on the two sides of Hu line. Acta Geograph Sinica 72:148-60.

Li R, Cui LL, Li JL, Zhao A, Fu HB, Wu Y, Zhang LW, Kong LD, Chen JM, 2017d. Spatial and temporal variation of particulate matter and gaseous pollutants in China during 2014-2016. Atmos Environ 161:235-46.

Li YC, Wang XP, Zhu QS, Zhao H, 2014. Assessing the spatial and temporal differences in the impacts of factor allocation and urbanization on urban-rural income disparity in China, 20042010. Habitat Int 42:76-82.

Liu E, Feng Y, Yue Z, Zhang Q, Han T, 2019. Differences in the health behaviors of elderly individuals and influencing factors: Evidence from the Chinese longitudinal healthy longevity survey. Int J Health Plann Manage 34:e1520-32.

Liu XH, Yang QK, A TG, 2001. Extraction and application of relief of china based on DEM and GIS method. Bull Soil Water Conserv 21:57-59,62.

Liu YL, Luo KL, Lin XX, Gao X, Ni RX, Wang SB, Tian XL, 2014. Regional distribution of longevity population and chemical characteristics of natural water in Xinjiang, China. Sci Total Environ 473:54-62.

Ljungquist B, Berg S, Lanke J, McClearn GE, Pedersen NL, 1998. The effect of genetic factors for longevity: A comparison of identical and fraternal twins in the Swedish twin registry. J Gerontol a-Biol 53:M441-6.

Lv JM, Wang WY, Li YH, 2011. Effects of environmental factors on the longevous people in China. Arch Gerontol Geriat 53:200-5.

Magnolfi SU, Petruzzi E, Pinzani P, Malentacchi E, Pazzagli M, Antonini FM, 2007. Longevity index (LI\%) and centenarity index $(\mathrm{CI} \%)$ : new indicators to evaluate the characteristics of aging process in the Italian population. Arch Gerontol Geriat
44:271-6.

Mansour S, Al Kindi A, Al-Said A, Al-Said A, Atkinson P, 2021. Sociodemographic determinants of COVID-19 incidence rates in Oman: geospatial modelling using multiscale geographically weighted regression (MGWR). Sustain Cities Soc 65.

Mei L, Xue Y, de Leeuw G, Guang J, Wang Y, Li Y, Xu H, Yang L, Hou T, He X, Wu C, Dong J, Chen Z, 2011. Integration of remote sensing data and surface observations to estimate the impact of the Russian wildfires over Europe and Asia during August 2010. Biogeosciences 8:3771-91.

Montesanto A, De Rango F, Pirazzini C, Guidarelli G, Domma F, Franceschi C, Passarino G, 2017. Demographic, genetic and phenotypic characteristics of centenarians in Italy: Focus on gender differences. Mech Ageing Dev 165:68-74.

Oshan TM, Li ZQ, Kang W, Wolf LJ, Fotheringham AS, 2019. MGWR: A python implementation of multiscale geographically weighted regression for investigating process spatial heterogeneity and scale. Isprs Int J Geo-Inf 8.

Oshan TM, Smith JP, Fotheringham AS, 2020. Targeting the spatial context of obesity determinants via multiscale geographically weighted regression. Int J Health Geograph 19.

PCOSC and NBSC, 2012. Tabulation on the 2010 population censuses of the people's republic of China by county. China Statistic Press, Beijing, China.

Pes GM, Tolu F, Poulain M, Errigo A, Masala S, Pietrobelli A, Battistini NC, Maioli M, 2013. Lifestyle and nutrition related to male longevity in Sardinia: An ecological study. Nutr Metab Cardiovas 23:212-9.

Poulain M, Herm A, Pes G, 2013. The Blue Zones: areas of exceptional longevity around the world. Vienna Yearbook Popul Res 2013:87-108.

Poulain M, Pes GM, Grasland C, Carru C, Ferrucci L, Baggio G, Franceschi C, Deiana L, 2004. Identification of a geographic area characterized by extreme longevity in the Sardinia island: the AKEA study. Exp Gerontol 39:1423-9.

Robine JM, Cubaynes S, 2017. Worldwide demography of centenarians. Mech Ageing Dev 165:59-67.

Romanski J, Wu W, Anderson PJ, Austin PC, Rochon PA, 2015. Visualising the distribution of individuals of advanced age in Canada: linking census data to maps. Age Ageing 44:511-4.

Salleh SA, Abd Latif Z, Mohd WMNW, Chan A, 2012. Albedo pattern recognition and time-series analyses in malaysia. Int Arch Photogramm 39:235-40.

State Council of China, 2019. Notice on the launch of the seventh national population census. Available from: http://www. gov.cn/zhengce/content/2019-11/08/content_ 5450146.htm Accessed: 20 March 2021.

Song WJ, Li YH, Hao Z, Li HR, Wang WY, 2016. Public health in China: an environmental and socio-economic perspective. Atmos Environ 129:9-17.

Spann SJ, Ottinger MA, 2018. Longevity, metabolic disease, and community health. Prog Mol Biol Transl 155:1-9.

Su SL, Xiao R, Zhang Y, 2012. Multi-scale analysis of spatially varying relationships between agricultural landscape patterns and urbanization using geographically weighted regression. Appl Geogr 32:360-75.

Vaupel JW, Carey JR, Christensen K, Johnson TE, Yashin AI, Holm NV, Iachine IA, Kannisto V, Khazaeli AA, Liedo P, Longo VD, Zeng Y, Manton KG, Curtsinger JW, 1998. Biodemographic trajectories of longevity. Science 280:855-60.

Vierboom YC, Preston SH, 2020. Life beyond 65: Changing spatial patterns of survival at older ages in the United States, 2000-2016. J Gerontol B-Psychol 75:1093-103. 
Wang B, Bao JW, Peng JF, Zhang J, Wang P, 2018. An NDVI synthesis method for multi-temporal remote sensing images based on K-NN learning: a case based on GF-1 data. Remote Sens Lett 9:541-9.

Wang L, Li YH, Li HR, Holdaway J, Hao Z, Wang WY, Krafft T, 2016. Regional aging and longevity characteristics in China. Arch Gerontol Geriat 67:153-9.

Wang L, Wei BG, Li YH, Li HR, Zhang FY, Rosenberg M, Yang LS, Huang JX, Krafft T, Wang WY, 2014. A study of air pollutants influencing life expectancy and longevity from spatial perspective in China. Sci Total Environ 487:57-64.

Wang SB, Luo KL, Liu YL, Zhang SX, Lin XX, Ni RX, Tian XL, Gao X, 2015. Economic level and human longevity: Spatial and temporal variations and correlation analysis of per capita GDP and longevity indicators in China. Arch Gerontol Geriat 61:93-102.

Wu XD, Xiao Q, Wen JG, You DQ, Hueni A, 2019. Advances in quantitative remote sensing product validation: overview and current status. Earth-Sci Rev 196.

Xu LY, Kang P, Wei JJ, 2010. Evaluation of urban ecological carrying capacity: a case study of Beijing, China. Procedia Environ Sci 2:1873-80.

Xu W, Sun J, Liu Y, Xiao Y, Tian Y, Zhao B, Zhang X, 2019. Spatiotemporal variation and socioeconomic drivers of air pol- lution in China during 2005-2016. J Environ Manage 245:6675.

Xu X, Ma Y, Zhang X, Maisumu D, Zhao X, Gao J, Yasheng M, 2009. Serum sex hormone levels associated with aging and arterial blood pressure in the Uygur longevity people in Hetian Xinjiang Uygur Autonomous Region. Chinese J Hypertens 17:925-9

Yang DY, Ye C, Wang XM, Lu DB, Xu JH, Yang HQ, 2018. Global distribution and evolvement of urbanization and PM2.5 (19982015). Atmos Environ 182:171-8.

Yu H, Fotheringham AS, Li Z, Oshan T, Kang W, Wolf LJ, 2019. Inference in multiscale geographically weighted regression. Geogr Anal 52:87-106.

Zafeiris KN, 2020. Gender differences in life expectancy at birth in Greece 1994-2017. J Popul Res 37:73-89.

Zhang W, Wei M, 2016. The evaluation of the mortality and life expectancy of Chinese population. Popul J 38:18-28.

Zhao Z, Cheng Z, Shan J, Tu L, 2003. Marital, sexual behavior, sex hormone of Uygur Iongevity people in Hetian,XiJiang Uygur Autonomous Region. Chinese J Geriatr 22:490-493.

Zhu XB, Ma MG, Yang H, Ge W, 2017. Modeling the spatiotemporal dynamics of gross domestic product in China using extended temporal coverage nighttime light data. Remote Sens 9. 